\title{
PERANCANGAN DETAIL STRUKTUR LERENG DAN PERKERASAN JALAN PADA PROYEK PENAMBAHAN LAJUR RUAS KOPO - BUAH BATU TOL PURBALEUNYI
}

\author{
Aghnia Monica Saniy ${ }^{1}$, Syahril ${ }^{2}$, Atmy Verani R. S. ${ }^{2}$ \\ ${ }^{1}$ Mahasiswa DIV-Teknik Perancangan Jalan dan Jembatan Jurusan Teknik Sipil Politeknik Negeri \\ Bandung Jl. Gegerkalong Hilir Ds. Ciwaruga Bandung 40012. Email: aghniamonicasaniy@ gmail.com \\ ${ }^{2}$ Staf pengajar Jurusan Teknik Sipil Politeknik Negeri Bandung Jl. Gegerkalong Hilir Ds. Ciwaruga \\ Bandung 40012. Email: syahril_polban@yahoo.co.id; atmyvera@yahoo.com
}

\begin{abstract}
ABSTRAK
Proyek Pelebaran Lajur Ruas Kopo - Buah Batu Jalur B Tol Purbaleunyi adalah proyek penambahan lajur yang bertujuan untuk menanggulangi kemacetan yang terjadi di ruas tersebut. Pelebaran dilakukan dimulai dari KM 136+050 sampai KM 143+100. Berdasarkan hasil penyelidikan tanah, lokasi timbunan di KM 139+925 dan KM 142+750 memiliki kondisi tanah yang memiliki angka keamanan < 1,5 yang menunjukkan bahwa lereng timbunan tersebut tidak aman sehingga perlu dibuat perkuatan yaitu dinding penahan tanah. Selain itu, dilakukan perancangan perkerasan yang sesuai dengan kondisi tanah lapangan, perhitungan rencana anggaran biaya (RAB), dan perancangan metoda pelaksanaan pekerjaan. Perancangan dinding penahan tanah dimulai dengan mencari dimensi dinding penahan tanah dan menghitung gaya-gaya yang bekerja pada dinding penahan tanah. Setelah itu, dilakukan pengecekan terhadap stabilitas geser, guling, daya dukung dan penurunan. Untuk perancangan perkerasan dihitung dengan mempertimbangkan, kondisi tanah, lalu-lintas harian rata-rata (LHR), dan umur rencana menggunakan AASHTO 1993. Sementara untuk, RAB dihitung menggunakan AHSP Bina Marga 2013 dan metode pelaksanaan dibuat sesuai dengan kondisi lapangan. Berdasarkan hasil analisa, didapatkan dimensi dinding penahan tanah dengan lebar bawah $3 \mathrm{~m}$, lebar atas $0,3 \mathrm{~m}$, tinggi bagian bawah pondasi $0,5 \mathrm{~m}$ dan tinggi total dinding $4 \mathrm{~m}$. Dinding penahan tanah perlu ditambahkan tiang pancang untuk meningkatkan daya dukung, dengan jumlah tiang di KM 139+425 sebanyak 20 tiang diameter $40 \mathrm{~cm}$ yang menghasilkan daya dukung grup tiang $1878,421 \mathrm{KN}$, pergerseran kepala tiang sebesar $1,065 \mathrm{~cm}$, penurunan sebesar $1,29 \mathrm{~cm}$, dan angka keamanan lereng 2,335. Untuk jumlah tiang di KM 142+750 sebanyak 10 tiang diameter $30 \mathrm{~cm}$ yang menghasilkan daya dukung grup tiang 2049,398 $\mathrm{KN}$, pergerseran kepala tiang sebesar $1,009 \mathrm{~cm}$, penurunan sebesar 2,398 cm, dan angka kemanan lereng 1,883. Untuk jenis perkerasan yang sesuai dengan kondisi tanah di lapangan adalah perkerasan kaku dengan tebal aggregat kelas A $30 \mathrm{~cm}$, lean concrete $10 \mathrm{~cm}$, dan tebal pelat beton $27 \mathrm{~cm}$. Hasil rencana anggaran biaya seluruh pekerjaan adalah Rp 35.000.000.000 dengan metode pelaksanaan pekerjaan yang dilaksanakan pada siang hari.
\end{abstract}

Kata kunci : Tol Purbaleunyi, Dinding Penahan Tanah, Perkerasan Jalan, Rencana Anggaran Biaya, Metode Pelaksanaan

\section{Pendahuluan}

Jalan Tol Purbaleunyi adalah jalan tol yang menghubungkan Kabupaten Purwakarta - Kota Bandung - Cileunyi (Kabupaten Bandung) dengan panjang dengan panjang 88 kilometer. Jalan tol ini pada awalnya hanya terdiri dari ruas Padalarang - Cileunyi (Padaleunyi). Kemudian pada tahun 2003 - 2005 dilaksanakan pembangunan jalan tol ruas Cikampek Padalarang sehingga Jalan Tol Purbaleunyi menjadi lanjutan dari Jalan Tol JakartaCikampek. Dengan adanya Jalan Tol Purbaleunyi, perjalanan dari Kota Bandung ke
Kota Jakarta dan sebaliknya dapat ditempuh dengan waktu 2 jam. Perjalanan antar kota/kabupaten di Provinsi Jawa Barat pun relatif singkat, sehingga arus kendaraan di jalan tol pada akhir pekan dan hari libur menjadi padat. Untuk menanggulangi hal tersebut, pada tahun 2016 PT Jasa Marga melaksanakan pelebaran Jalan Tol Purbaleunyi Ruas Kopo - Buah Batu jalur B arah Jakarta agar mampu memperlancar arus kendaraan serta meningkatkan kenyamanan pengguna jalan tol.

Pada saat ini, Jalan Tol Purbaleunyi Ruas Kopo - Buah Batu Jalur B arah Jakarta memiliki 2

PERANCANGAN DETAIL STRUKTUR LERENG DAN PERKERASAN JALAN PADA PROYEK PENAMBAHAN LAJUR RUAS KOPO - BUAH BATU TOL PURBALEUNYI

Aghnia Monica Saniy, Syahril, Atmy Verani 
lajur. Sehingga dengan ada proyek penambahan lajur, Ruas Kopo - Buah Batu Jalur B bertambah menjadi 3 lajur. Dalam pekerjaan pelebaran jalan tol ini, lebar lajur tambahan yang akan dibangun adalah 3,6 meter, lebar bahu jalan sebesar 2,5 meter, dengan rounding selebar 1,5 $\mathrm{m}$.

Dengan adanya pekerjaan pelebaran jalan tol ini, perlu dilakukan penyelidikan terhadap potensi kelongsoran. Selain dengan kondisi tanah yang tidak baik, beban kendaraan yang besar pun menjadi salah satu penyebab besarnya potensi kelongsoran. Kelongsoran ini dapat menyebabkan badan jalan rusak sehingga harus dicegah. Oleh karena itu, topik yang akan dibahas dalam tugas akhir ini adalah perancangan detail struktur lereng dan perancangan struktur perkerasan yang sesuai dengan kondisi lapangan. Ruas Kopo - Buah Batu dapat dilihat pada Gambar 1, sedangkan untuk $\mathrm{k}$ ondisi lapangan dapat dilihat pada Gambar 2.

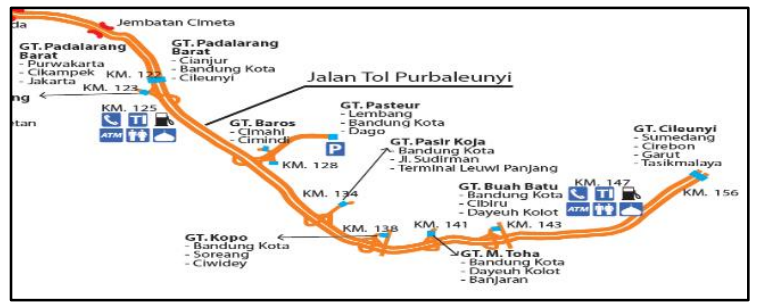

Gambar 1. Ruas Kopo - Buah B

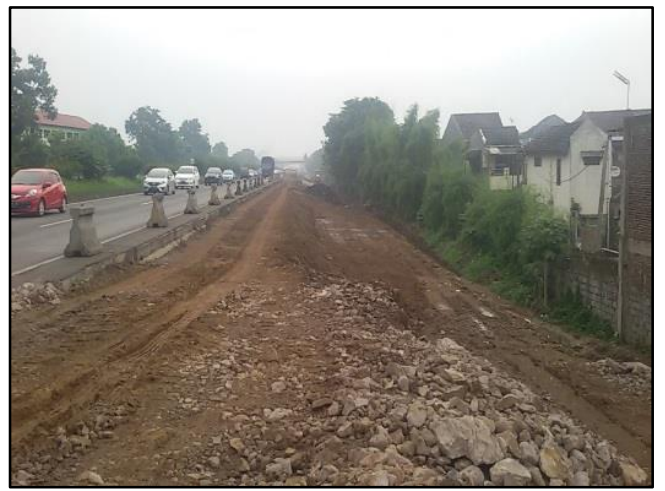

Gambar 2. Kondisi Lapangan

\section{II.Metodologi}

Metodologi merupakan suatu tata cara yang terperinci dan dibuat sistematis mengenai tahapan-tahapan penyusunan penelitian untuk mempermudah analisa dan perancangan. Metodologi penyusunan tugas akhir dituangkan ke dalam diagram alir pada Gambar 3.

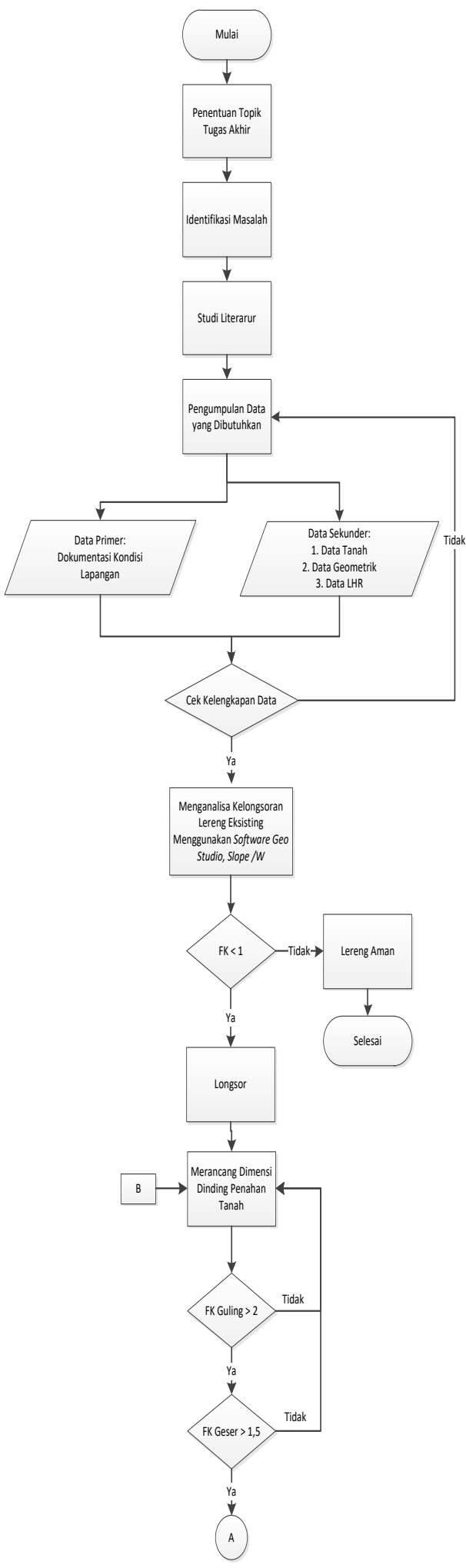

Gambar 3. Metodologi penelitian

PERANCANGAN DETAIL STRUKTUR LERENG DAN PERKERASAN JALAN PADA PROYEK PENAMBAHAN LAJUR RUAS KOPO - BUAH BATU TOL PURBALEUNYI

Aghnia Monica Saniy, Syahril, Atmy Verani 
Tabel 2. Data Tanah KM 139+925

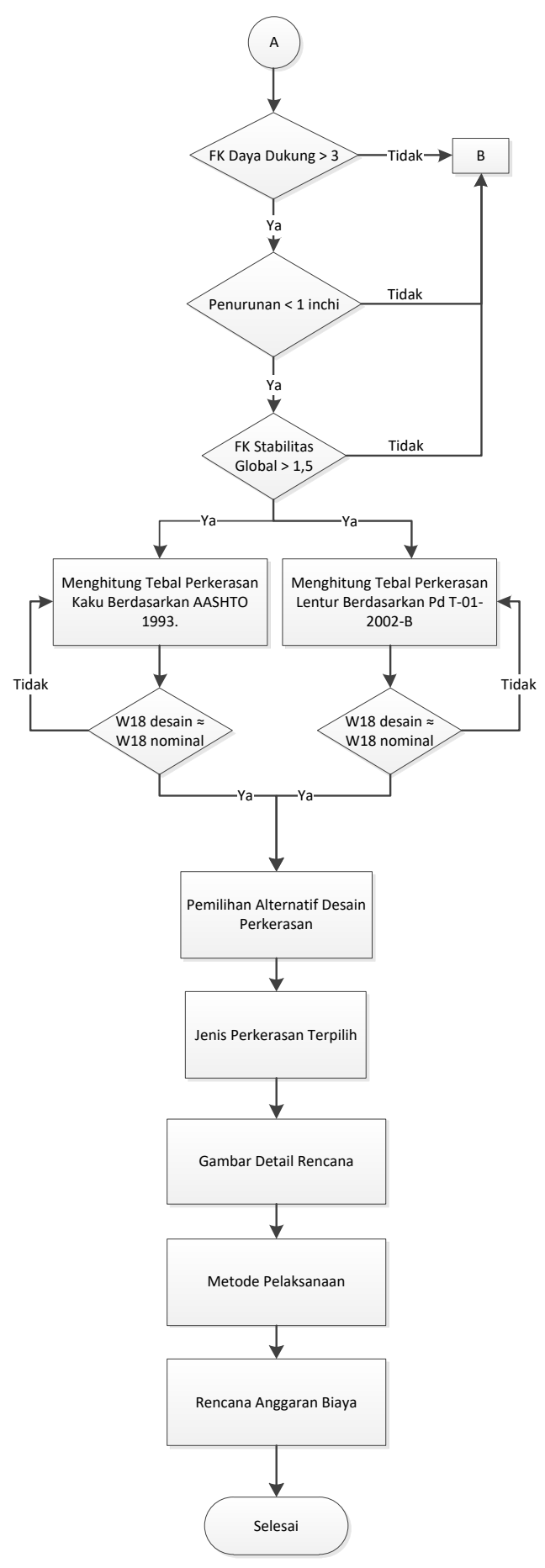

Gambar 3. Metodologi penelitian

\section{IV.Hasil dan Analisis}

Pada penelitian ini hal yang pertama kali dilakukan adalah analisa kelongsoran menggunakan GeoStudio Slope /W, dengan data masukan pada Tabel 2 dan Tabel 3.

\begin{tabular}{|c|c|c|c|}
\hline $\begin{array}{c}\text { Kedalaman } \\
\text { Tanah (m) }\end{array}$ & \multicolumn{3}{|c|}{ Parameter Tanah } \\
\cline { 2 - 4 } & $\begin{array}{c}\text { Berat isi } \\
\left(\text { ton } / \mathrm{m}^{3}\right)\end{array}$ & $\begin{array}{c}\text { Kohesi } \\
\left(\mathrm{kg} / \mathrm{cm}^{2}\right)\end{array}$ & $\begin{array}{c}\text { Sudut } \\
\text { geser }\left({ }^{\circ}\right)\end{array}$ \\
\hline $0.00-3.50$ & 1,568 & 0,06 & 8,6 \\
\hline $3.50-7.50$ & 1,584 & 0,05 & 8,1 \\
\hline $7.50-$ & 1,562 & 0,08 & 6,1 \\
11.182 & & 0,65 & 10 \\
\hline $\begin{array}{c}\text { Material } \\
\text { Timbunan }\end{array}$ & 1,800 & & \\
\hline
\end{tabular}

Tabel 3. Data Tanah KM 142+750

\begin{tabular}{|c|c|c|c|}
\hline \multirow{2}{*}{$\begin{array}{c}\text { Kedalaman } \\
\text { Tanah (m) }\end{array}$} & \multicolumn{3}{|c|}{ Parameter Tanah } \\
\cline { 2 - 4 } & $\begin{array}{c}\text { Berat isi } \\
\left(\text { ton } / \mathrm{m}^{3}\right)\end{array}$ & $\begin{array}{c}\text { Kohesi } \\
\left(\mathrm{kg} / \mathrm{cm}^{2}\right)\end{array}$ & $\begin{array}{c}\text { Sudut } \\
\text { geser }\left({ }^{\circ}\right)\end{array}$ \\
\hline $0.00-3.50$ & 1,568 & 0,06 & 8,6 \\
\hline $3.50-7.50$ & 1,584 & 0,05 & 8,1 \\
\hline $7.50-$ & 1,562 & 0,08 & 6,1 \\
11.182 & 1,800 & 0,65 & 10 \\
\hline $\begin{array}{c}\text { Material } \\
\text { Timbunan }\end{array}$ & & & \\
\hline
\end{tabular}

Hasil analisa kelongsoran menggunakan GeoStudio Slope $/ W$ yang ditunjukkan pada Gambar 4 dan Gambar 5.

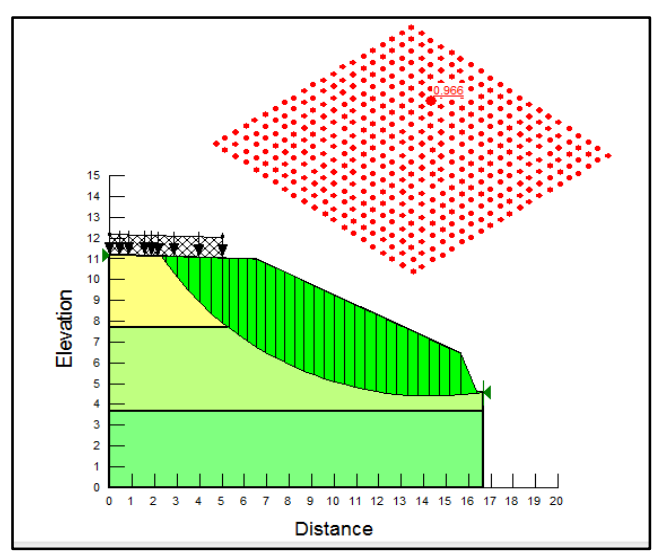

Gambar 4. Hasil Analisa Kelongsoran Menggunakan Software Geostudio Slope / W KM 139+925

PERANCANGAN DETAIL STRUKTUR LERENG DAN PERKERASAN JALAN PADA PROYEK PENAMBAHAN LAJUR RUAS KOPO - BUAH BATU TOL PURBALEUNYI

Aghnia Monica Saniy, Syahril, Atmy Verani 


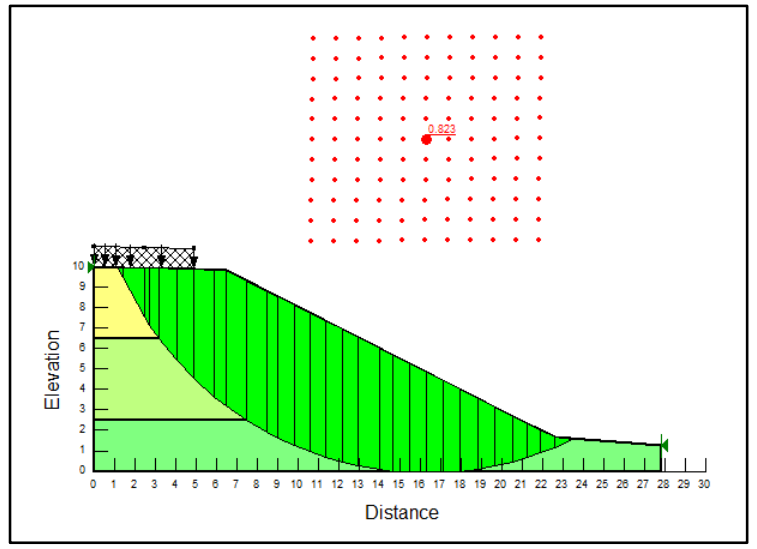

Gambar 5. Hasil Analisa Kelongsoran Menggunakan Software Geostudio Slope /W KM 142+750

Dari hasil analisa tersebut menunjukkan bahwa lereng tidak aman FK < 1,5 dan harus ditambah perkuatan lereng yaitu dinding penahan tanah.

Gambar tipikal dinding penahan tanah rencana.

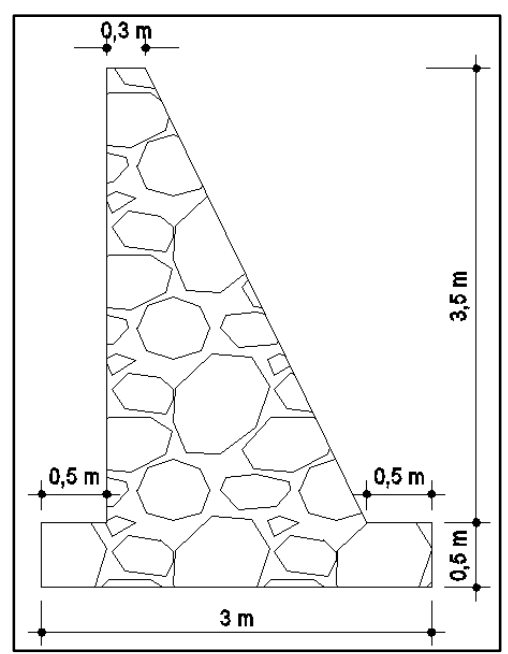

Gambar 6. Dinding Penahan Tanah Rencana

Dengan parameter dinding penahan tanah sebagai berikut:

a. Tipe dinding penahan tanah:Gravity Wall

b. Material:Pasangan Batu

c. Berat isi pasangan batu $(\mathrm{y}): 22 \mathrm{kN} / \mathrm{m}^{3}$

d. Kohesi (c) : $200 \mathrm{kN} / \mathrm{m}^{2}$

e. Sudut geser $(\varphi)$ : $45^{\circ}$

Penempatan dinding penahan tanah dapat dilihat pada Gambar 7 (a) dan Gambar 7 (b).

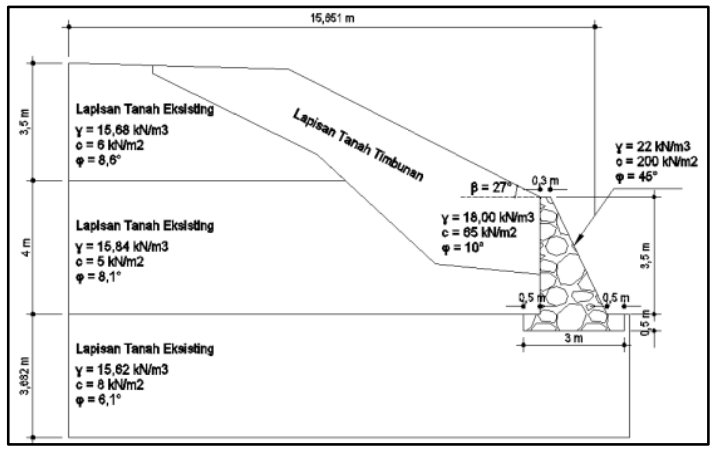

Gambar 7 (a). Denah Dinding Penahan Tanah KM $139+925$

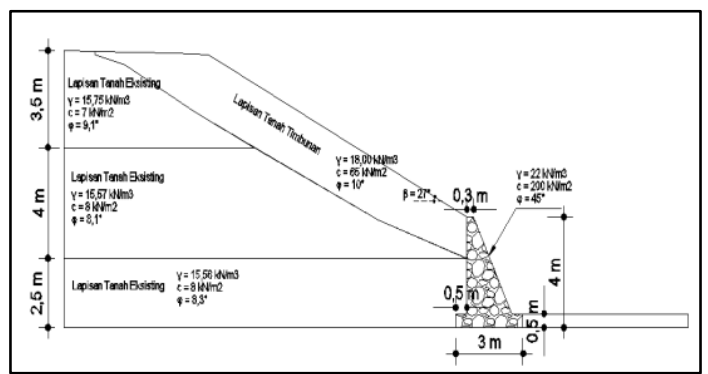

Gambar 7 (b). Denah Dinding Penahan Tanah KM $142+750$

\section{a. Perencanaan Dinding Penahan Tanah KM 139+925}

Hasil perhitungan tekanan tanah aktif pada KM 139+925 dapat dilihat pada Tabel 4.

Tabel 4. Rekapitulasi Tekanan Tanah Aktif

\begin{tabular}{|c|c|c|c|c|}
\hline $\begin{array}{c}\text { Lapisan } \\
\text { Tanah }\end{array}$ & $\begin{array}{c}\text { Tekanan } \\
\text { Tanah } \\
\text { Aktif } \\
\text { Horizontal } \\
\text { Akibat } \\
\text { Berat Isi } \\
\text { Tanah (kN) }\end{array}$ & $\begin{array}{c}\text { Tekanan } \\
\text { Tanah } \\
\text { Aktif } \\
\text { Vertikal } \\
\text { Akibat } \\
\text { Berat Isi } \\
\text { Tanah } \\
\text { (kN) }\end{array}$ & $\begin{array}{c}\text { Tekanan } \\
\text { Tanah } \\
\text { Aktif } \\
\text { Akibat } \\
\text { Beban } \\
\text { Kendaraan } \\
\text { (kN) }\end{array}$ & $\begin{array}{c}\text { Tekanan } \\
\text { Tanah } \\
\text { Aktif } \\
\text { Akibat } \\
\text { Kohesi } \\
\text { (kN) }\end{array}$ \\
\hline 1 & 52,429 & 26,712 & 35,821 & \multirow[t]{3}{*}{61,189} \\
\hline 2 & 81,619 & 8,578 & 18,304 & \\
\hline 3 & 29,487 & & 6,059 & \\
\hline$\Sigma$ & 163,532 & 35,29 & 60,183 & 61,189 \\
\hline
\end{tabular}

Tekanan tanah yang terjadi adalah

$\mathrm{Pa}$ Total $=\sum \mathrm{Pa}-2 \mathrm{c} \sqrt{ } \mathrm{Ka} \mathrm{H}$

$=163,532+60,183-61,189$

$=162,527 \mathrm{kN}$

$\mathrm{Hc} \quad=2 \mathrm{c} /(\gamma \sqrt{\mathrm{Ka}})$

$=(2 \times 8) /(15,62 \sqrt{ } 0,808)$

$=1,140 \mathrm{~m}$

$\mathrm{Z}=(\mathrm{H}-\mathrm{hc}) / 3$

$=(4,255-1,140) / 3=1,038 \mathrm{~m}$

PERANCANGAN DETAIL STRUKTUR LERENG DAN PERKERASAN JALAN PADA PROYEK PENAMBAHAN LAJUR RUAS KOPO - BUAH BATU TOL PURBALEUNYI

Aghnia Monica Saniy, Syahril, Atmy Verani 
Gaya-gaya yang bekerja pada dinding dapat dilihat pada Gambar 8.

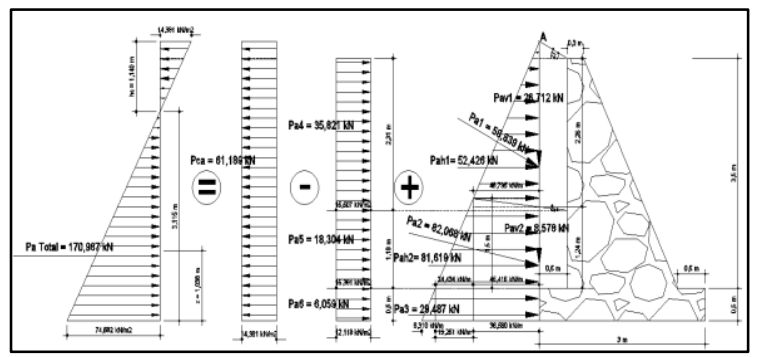

Gambar 8. Diagram Gaya Yang Bekerja Pada Dinding Penahan Tanah Rencana

Perhitungan momen tahanan dihitung berdasarkan, berat dinding penahan tanah. Untuk memudahkan perhitungan momen, dilakukan pembagian segmen luas dinding penahan tanah dan berat tanah di atas pelat dinding penahan tanah yang ditunjukan pada Gambar 9.

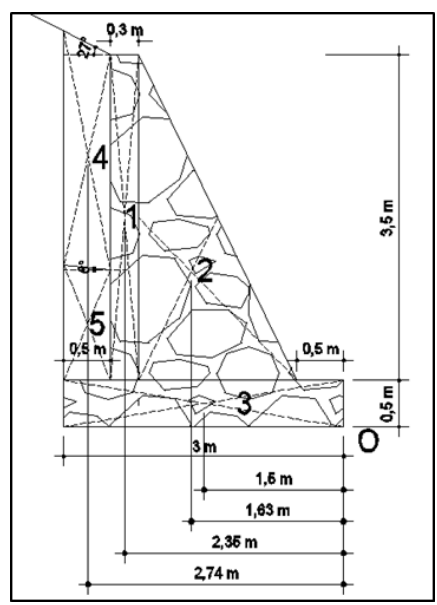

Gambar 9. Pembagian Segmen Untuk Menghitung Momen Tahanan

Hasil perhitungan momen tahanan pada KM 139+925 dapat dilihat pada Tabel 5.

Tabel 5. Gaya Vertikal Dan Momen Terhadap Titik $\mathrm{O}$

\begin{tabular}{|c|c|c|c|c|c|c|}
\hline No & $\begin{array}{c}\text { Segm } \\
\text { en }\end{array}$ & $\begin{array}{c}\text { Luas } \\
\left(\mathbf{m}^{2}\right)\end{array}$ & $\begin{array}{c}\text { Berat } \\
\text { Volume } \\
(\mathbf{k N / m 3} \\
)\end{array}$ & $\begin{array}{c}\text { Gaya } \\
\text { Vertika } \\
\mathbf{i ~ W} \\
(\mathbf{k N})\end{array}$ & $\begin{array}{c}\text { Jarak } \\
\text { dari O } \\
(\mathbf{m})\end{array}$ & $\begin{array}{c}\text { Momen } \\
\mathbf{k e} \mathbf{O} \\
(\mathbf{k N m})\end{array}$ \\
\hline 1. & $\mathrm{~W} 1$ & 1,05 & 22 & 23,1 & 2,35 & 54,285 \\
\hline 2. & $\mathrm{~W} 2$ & 2,975 & 22 & 65,45 & 1,633 & 106,902 \\
\hline 3. & $\mathrm{~W} 3$ & 1,5 & 22 & 33 & 1,5 & 49,500 \\
\hline 4. & $\mathrm{~W} 4$ & 1,206 & 18 & 21,7 & 2,74 & 59,458 \\
\hline 5. & $\mathrm{~W} 5$ & 0,608 & 15,84 & 9,633 & 2,74 & 26,394 \\
\hline 6. & $\mathrm{q}$ & & & $\begin{array}{c}15 \times 0,5 \\
=7,5\end{array}$ & 2,75 & 20,625 \\
\hline & & & $\sum \mathbf{W}$ & $\mathbf{1 6 0 , 3 8 3}$ & $\sum \mathbf{M W}$ & $\mathbf{3 1 7 , 1 6 4}$ \\
\hline
\end{tabular}

Momen Dorong $=$ Pah $\mathrm{x} Z$

$$
=162,257 \mathrm{kN} \times 1,038 \mathrm{~m}
$$

$$
=168,765 \mathrm{kNm}
$$

Stabilitas Geser $=\frac{\sum R h}{\sum P a h}$

$$
\begin{aligned}
& =\frac{\sum \mathrm{CdB}+\left(\sum \mathrm{W}+\sum \text { Pav }\right) \operatorname{tg} \delta \mathrm{b}}{\sum \text { Pah }} \\
& =\frac{131,621}{162,527}=0,810>1,5 \ldots \mathrm{OK}
\end{aligned}
$$

Stabilitas Guling $=\frac{\sum M w+\left(\sum \operatorname{Pav} \times B\right)}{\sum M g l}$

$$
\begin{aligned}
& =\frac{317,164+(35,291 \times 3)}{168,765} \\
& =2,507>2 \ldots \mathrm{OK}
\end{aligned}
$$

Stabilitas Daya Dukung $=\frac{q u}{q^{\prime}}=\frac{25,067}{75,290}$

$$
=0,333>3 \ldots \text { Not } \mathrm{OK}
$$

Maka harus ditambah tiang pancang.

Selanjutnya dilakukan perhitungan analisa global menggunakan software Geo Studio Slope/W yang dapat dilihat pada Gambar 9.

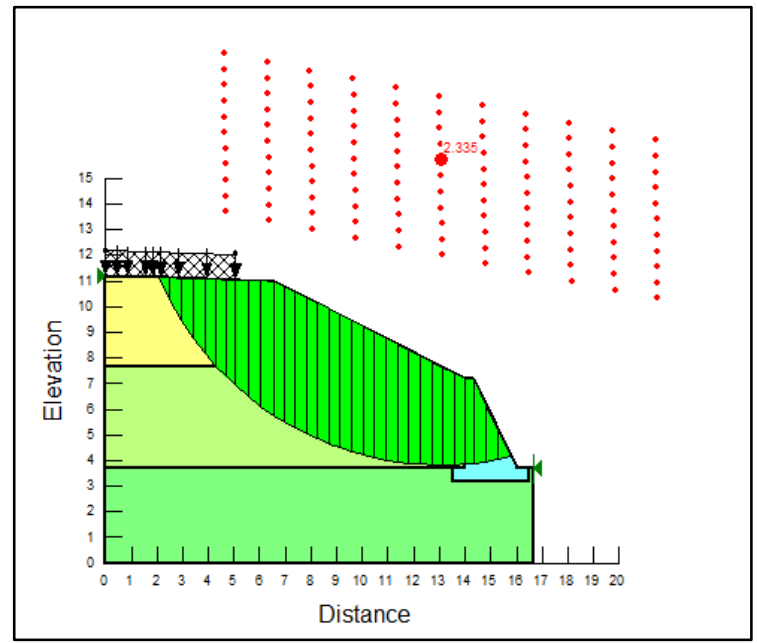

Gambar 10. Analisa Global Menggunakan software Geostudio Slope /W

Hasil analisa global menggunakan software Geo Studio Slope/W menunjukkan angka keamanan 2,335 > 1,5 yang menunjuukan bahwa lereng aman.

Selanjutnya dilakukan perhitungan analisa global menggunakan cara manual dengan menggunakan metode Bishop yang diharuskan menggambar lereng dan irisan lereng seperti pada Gambar 11.

PERANCANGAN DETAIL STRUKTUR LERENG DAN PERKERASAN JALAN PADA PROYEK PENAMBAHAN LAJUR RUAS KOPO - BUAH BATU TOL PURBALEUNYI

Aghnia Monica Saniy, Syahril, Atmy Verani 


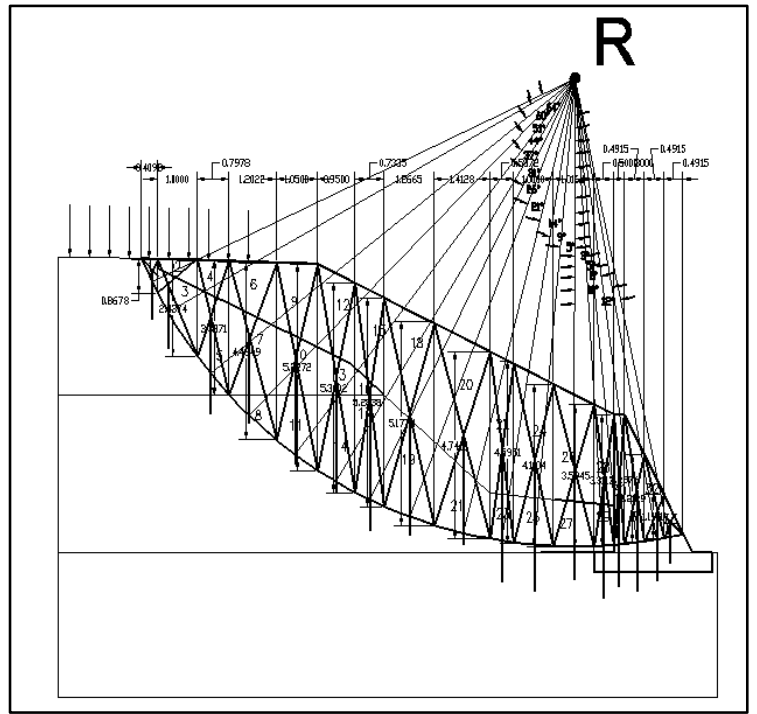

Gambar 11. Pembagian Irisan Lereng

Dari hasil perhitungan secara manual didapatkan nilai faktor keamanan sebesar 1,578 yang hampir sama dengan hasil perhitungan dengan menggunakan software GeoStudio Slope/W sebesar 2,130 yang menunjukan bahwa lereng aman $(>1,5)$.

Perhitungan pile cap adalah sebagai berikut:

- Momen yang bekerja pada balok

$$
\begin{aligned}
M= & 1 / 8 \times \mathrm{q} \times \mathrm{L}^{2} \\
\mathrm{M}= & 1 / 8 \times(\text { berat sendiri balok }+ \text { berat DPT) } \mathrm{x} \\
& \mathrm{L}^{2}
\end{aligned}
$$

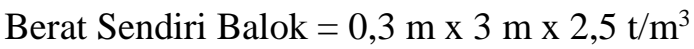

$$
=2,25 \mathrm{t} / \mathrm{m}
$$

Berat DPT $=16,623 \mathrm{t} / \mathrm{m}$

$\mathrm{M}=1 / 8 \times(2,25+16,623) \times 10^{2}$

$\mathrm{M}=231,416$ Ton.m

- Jarak bersih pile cap $(\mathrm{d})=234 \mathrm{~mm}$

- $\rho=63,070$

- Panjang penyaluran $(\mathrm{z})=1096,436 \mathrm{~mm}$

- $\mathrm{As}_{\text {total }}=8276,946 \mathrm{~mm}^{2}, \mathrm{n}=11$ buah

- Jarak antar tulangan $=295 \mathrm{~mm}$

- Vc $=2670525 \mathrm{~N}$

$-\phi \mathrm{Vn}=0,75 \times \mathrm{Vc}=2002893,750>\mathrm{Vu}=$

$1816791,730 \mathrm{~N}$, maka tidak diperlukan tulangan sengkang, karena gaya geser dapat dipikul oleh tulangan utama D32-295 atau bisa digunakan tulangan sengkang minimum yaitu D12-200.

Perhitungan tiang pancang adalah sebagai berikut:

Qs $=107,109$ ton

$\mathrm{Qb}=120,105$ ton

$\mathrm{Qu}=281,774$ ton

$\mathrm{Qa}=939,25 \mathrm{kN}$

Dari hasil perhitungan didapatkan jumlah tiang 2 buah diameter 40 dengan tinggi 28 meter mampu menahan beban DPT sepanjang $10 \mathrm{~m}$.

Beban Total 179,502 kN x $10 \mathrm{~m}=1795,017 \mathrm{kN}$

$\mathrm{Eg}=0,999$

Qag $=1878,421 \mathrm{kN}>1795,017 \mathrm{kN} \ldots \mathrm{OK}$

Ss $=0,4372$

$\mathrm{Sg}=1,2958 \mathrm{~cm}<2,54 \mathrm{~cm}$

$\delta_{\mathrm{x}}=0,00574 \mathrm{~m}=0,574 \mathrm{~cm}<2,54 \mathrm{~cm}(\mathrm{OK})$

$\delta_{\mathrm{y}}=0,000024 \mathrm{~m}=0,002 \mathrm{~cm}<2,54 \mathrm{~cm}(\mathrm{OK})$

$\alpha=0,00313$ radial

\section{b. Perencanaan Dinding Penahan Tanah KM 142+750:}

\begin{tabular}{|c|c|c|c|c|}
\hline $\begin{array}{c}\text { Lapisan } \\
\text { Tanah }\end{array}$ & $\begin{array}{c}\text { Tekanan } \\
\text { Tanah } \\
\text { Aktif } \\
\text { Horizontal } \\
\text { Akibat } \\
\text { Berat Isi } \\
\text { Tanah } \\
\text { (kN) }\end{array}$ & $\begin{array}{c}\text { Tekanan } \\
\text { Tanah } \\
\text { Aktif } \\
\text { Vertikal } \\
\text { Akibat } \\
\text { Berat Isi } \\
\text { Tanah } \\
\text { (kN) }\end{array}$ & $\begin{array}{c}\text { Tekanan } \\
\text { Tanah } \\
\text { Aktif } \\
\text { Akibat } \\
\text { Beban } \\
\text { Kendaraan } \\
\text { (kN) }\end{array}$ & $\begin{array}{c}\text { Tekanan } \\
\text { Tanah } \\
\text { Aktif } \\
\text { Akibat } \\
\text { Kohesi } \\
\text { (kN) }\end{array}$ \\
\hline 1 & 17,616 & 8,976 & 19,931 & \multirow[t]{3}{*}{58,866} \\
\hline 2 & 8,413 & 2,897 & 28,039 & \\
\hline 3 & 99,399 & & & \\
\hline$\Sigma$ & 125,428 & 11,873 & 47,970 & 58,866 \\
\hline
\end{tabular}

Hasil perhitungan tekanan tanah aktif pada KM 142+750 dapat dilihat pada Tabel 6 .

Tabel 6. Rekapitulasi Tekanan Tanah Aktif

Tekanan tanah yang terjadi adalah

$\mathrm{Pa}$ Total $=\sum \mathrm{Pa}-2 \mathrm{c} \sqrt{ } \mathrm{Ka} \mathrm{H}$

$$
\begin{aligned}
& =125,428+47,970-58,866 \\
& =114,532 \mathrm{kN}
\end{aligned}
$$

PERANCANGAN DETAIL STRUKTUR LERENG DAN PERKERASAN JALAN PADA PROYEK PENAMBAHAN LAJUR RUAS KOPO - BUAH BATU TOL PURBALEUNYI

Aghnia Monica Saniy, Syahril, Atmy Verani 


$$
\begin{aligned}
\mathrm{Hc} & =2 \mathrm{c} /(\gamma \sqrt{ } \mathrm{Ka}) \\
& =(2 \times 8) /(15,56 \sqrt{ } 0,748) \\
& =1,189 \mathrm{~m} \\
\mathrm{Z} & =(\mathrm{H}-\mathrm{hc}) / 3 \\
& =(4,255-1,189) / 3=1,022 \mathrm{~m}
\end{aligned}
$$

Gaya-gaya yang bekerja pada dinding dapat dilihat pada Gambar 11.

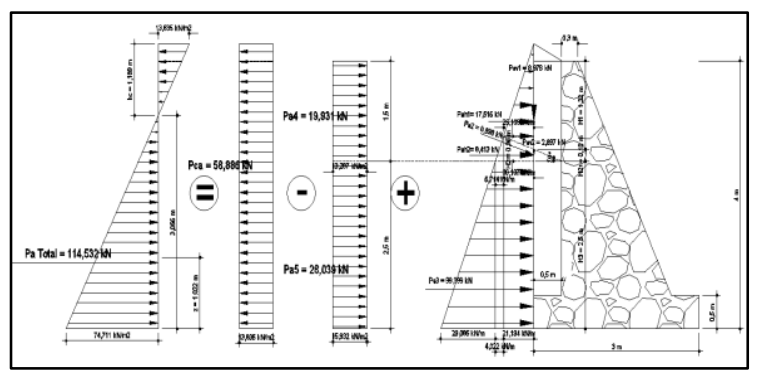

Gambar 12. Diagram Gaya Yang Bekerja Pada Dinding Penahan Tanah Rencana

Perhitungan momen tahanan dihitung berdasarkan, berat dinding penahan tanah. Untuk memudahkan perhitungan momen, dilakukan pembagian segmen luas dinding penahan tanah dan berat tanah di atas pelat dinding penahan tanah yang ditunjukan pada Gambar 12.

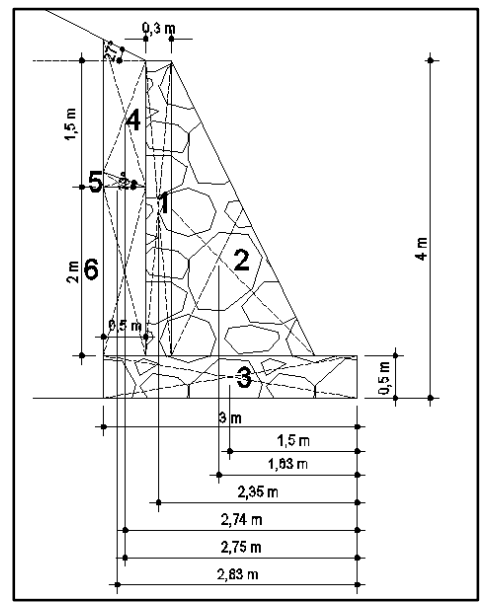

Gambar 13. Pembagian Segmen Untuk Menghitung Momen Tahanan

Hasil perhitungan momen tahanan pada KM 142+750 dapat dilihat pada Tabel 7 .
Tabel 7. Gaya Vertikal Dan Momen Terhadap Titik $\mathrm{O}$

\begin{tabular}{|c|c|c|c|c|c|c|}
\hline No & Segmen & $\begin{array}{c}\text { Luas } \\
\left(\mathbf{m}^{2}\right)\end{array}$ & $\begin{array}{c}\text { Berat } \\
\text { Volume } \\
(\mathbf{k N} / \mathbf{m} 3 \\
)\end{array}$ & $\begin{array}{c}\text { Gaya } \\
\text { Vertikal } \\
\mathbf{W}(\mathbf{k N})\end{array}$ & $\begin{array}{c}\text { Jarak } \\
\text { dari O } \\
(\mathbf{m})\end{array}$ & $\begin{array}{c}\text { Momen ke } \\
\mathbf{O}(\mathbf{k N m})\end{array}$ \\
\hline 1. & $\mathrm{~W} 1$ & 1,05 & 22 & 23,1 & 2,35 & 54,485 \\
\hline 2. & $\mathrm{~W} 2$ & 2,975 & 22 & 65,45 & 1,63 & 106,902 \\
\hline 3. & $\mathrm{~W} 3$ & 1,5 & 22 & 33 & 1,5 & 49,500 \\
\hline 4. & $\mathrm{~W} 4$ & 0,77 & 18 & 13,81 & 2,74 & 37,833 \\
\hline 5. & $\mathrm{~W} 5$ & 0,05 & 15,57 & 0,76 & 2,83 & 2,155 \\
\hline 6. & $\mathrm{~W} 6$ & 1 & 15,56 & 15,56 & 2,75 & 42,790 \\
\hline 7. & $\mathrm{q}$ & & & $15 \times 0,5=$ & 2,75 & 314,090 \\
& & & & 7,5 & & \\
\hline & & & $\sum \mathbf{W}$ & $\mathbf{1 5 9 , 1 7 9}$ & $\sum \mathbf{M W}$ & $\mathbf{3 1 4 , 0 9 0}$ \\
\hline
\end{tabular}

Stabilitas Geser $=\frac{\sum R h}{\sum P a h}$

$$
\begin{aligned}
& =\frac{\sum \mathrm{Cd} \mathrm{B}+\left(\sum \mathrm{W}+\sum \mathrm{Pav}\right) \operatorname{tg} \delta \mathrm{b}}{\sum \text { Pah }} \\
& =\frac{118,078}{114,532}=1,031>1,5 \ldots \mathrm{OK}
\end{aligned}
$$

Stabilitas Guling $=\frac{\sum M w+\left(\sum \text { Pav } \times B\right)}{\sum M g l}$

$$
\begin{aligned}
& =\frac{314,090+(11,872 \times 3)}{117,036} \\
& =2,988>2 \ldots \mathrm{OK}
\end{aligned}
$$

Stabilitas Daya Dukung $=\frac{q u}{q^{\prime}}=\frac{38,062}{62,876}$

$$
=0,605>3 \ldots \text { Not } \mathrm{OK}
$$

Maka harus ditambah tiang pancang.

Selanjutnya dilakukan perhitungan analisa global menggunakan software Geo Studio Slope/W yang dapat dilihat pada Gambar 13.

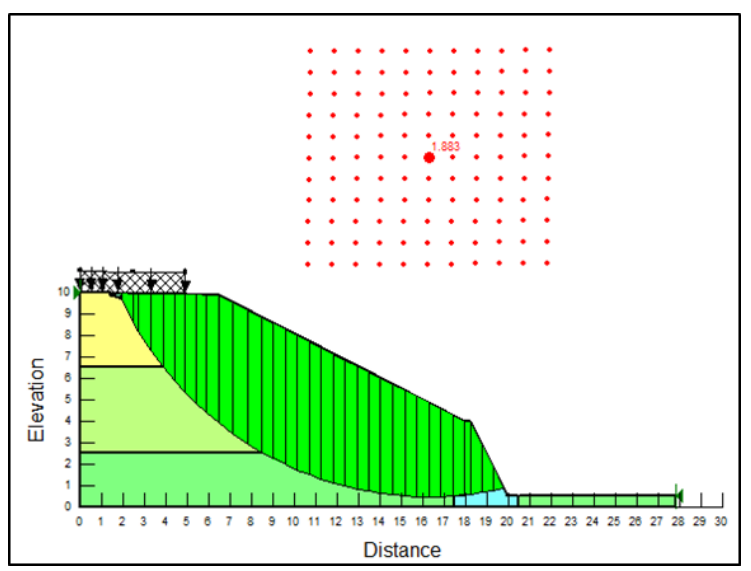

Gambar 13. Analisa Global Menggunakan software Geostudio Slope /W

Hasil analisa global menggunakan software Geo Studio Slope/W menunjukkan angka keamanan

PERANCANGAN DETAIL STRUKTUR LERENG DAN PERKERASAN JALAN PADA PROYEK PENAMBAHAN LAJUR RUAS KOPO - BUAH BATU TOL PURBALEUNYI 
$1,883>1,5$ yang menunjuukan bahwa lereng aman.

Selanjutnya dilakukan perhitungan analisa global menggunakan cara manual dengan menggunakan metode Bishop yang diharuskan menggambar lereng dan irisan lereng seperti pada Gambar 14.

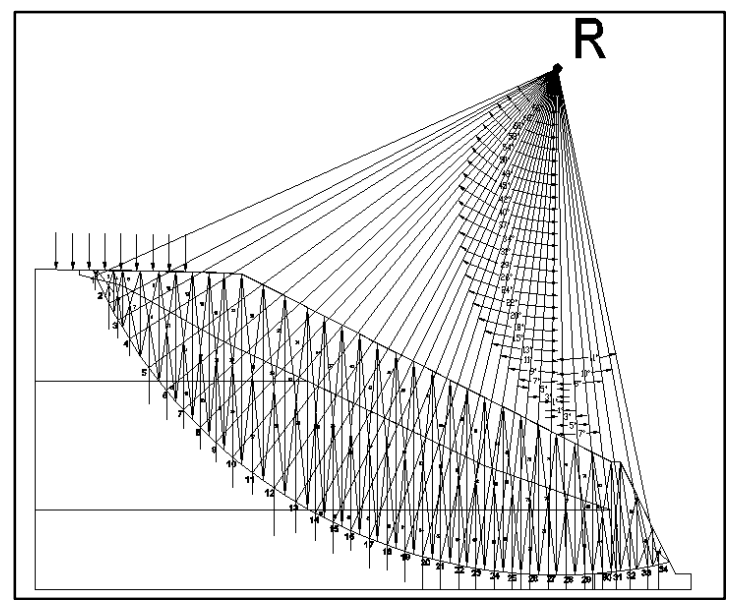

Gambar 14. Pembagian Irisan Lereng

Dari hasil perhitungan secara manual didapatkan nilai faktor keamanan sebesar 1,578 yang hampir sama dengan hasil perhitungan dengan menggunakan software GeoStudio Slope/W sebesar 1,578 yang menunjukan bahwa lereng aman $(>1,5)$.

Perhitungan pile cap adalah sebagai berikut:

- Momen yang bekerja pada balok

$$
\begin{aligned}
M= & 1 / 8 \times \mathrm{q} \times \mathrm{L}^{2} \\
\mathrm{M}= & 1 / 8 \times \text { (berat sendiri balok + berat DPT) } \mathrm{x} \\
& \mathrm{L}^{2}
\end{aligned}
$$

Berat Sendiri Balok $=0,3 \mathrm{~m} \mathrm{x} 3 \mathrm{~m} \mathrm{x} 2,5 \mathrm{t} / \mathrm{m}^{3}$

$$
=2,25 \mathrm{t} / \mathrm{m}
$$

Berat DPT $=15,918 \mathrm{t} / \mathrm{m}$

$\mathrm{M}=1 / 8 \times(2,25+15,918) \times 10^{2}$

$M=227,099$ Ton.m

- Jarak bersih pile cap $(\mathrm{d})=234 \mathrm{~mm}$

- $\rho=62,894$

- Panjang penyaluran $(\mathrm{z})=1095,066 \mathrm{~mm}$

- $\mathrm{As}_{\text {total }}=8132,702 \mathrm{~mm}^{2}, \mathrm{n}=11$ buah

- Jarak antar tulangan $=295 \mathrm{~mm}$

$-\mathrm{Vc}=2670525 \mathrm{~N}$ $-\phi \mathrm{Vn}=0,75 \times \mathrm{Vc}=2002893,750>\mathrm{Vu}=$ $1828828,541 \mathrm{~N}$, maka tidak diperlukan tulangan sengkang, karena gaya geser dapat dipikul oleh tulangan utama D32-295 atau bisa digunakan tulangan sengkang minimum yaitu D12-200.

Perhitungan tiang pancang adalah sebagai berikut :

Qs $=131,246$ ton

$\mathrm{Qb}=82,763$ ton

$\mathrm{Qu}=307,419$ ton

$\mathrm{Qa}=1024,73 \mathrm{kN}$

Jumlah tiang 2 buah diameter 30 dengan tinggi 26 meter mampu menahan beban DPT sepanjang $10 \mathrm{~m}$.

Beban Total 181,6792 kN x $10 \mathrm{~m}=1816,792 \mathrm{kN}$

$\mathrm{Eg}=0,999$

$\mathrm{Qag}=2049,398 \mathrm{kN}>1816,792 \mathrm{kN} \ldots$ OK

$\mathrm{Ss}=0,7583 \mathrm{~cm}$

$\mathrm{Sg}=2,398 \mathrm{~cm}<2,54 \mathrm{~cm}$

$\delta_{\mathrm{x}}=0,0010086 \mathrm{~m}=1,009 \mathrm{~cm}<2,54 \mathrm{~cm}(\mathrm{OK})$

$\delta_{\mathrm{y}}=0,00003 \mathrm{~m}=0,003 \mathrm{~cm}<2,54 \mathrm{~cm}(\mathrm{OK})$

$\alpha=0,00716$ radial

\section{c. Perencanaan Perkerasan Lentur}

Perencanaan perkerasan lentur dengan parameter sebagai berikut:

Fungsi jalan

: Arteri primer

Status jalan

: Jalan

Nasional

Jumlah Lajur Jalan Eksiting : 2 Lajur

Jumlah Lajur rencana $\quad: 3$ Lajur

Lebar Lajur

$: 3,60 \mathrm{~m}$

Lebar bahu

$: 2,50 \mathrm{~m}$

Umur rencana

: 10 tahun

$\mathrm{Zr}$

: $-1,282$

So

: 0,45

Po

$: 4,2$

$\mathrm{Pt}$

$\triangle \mathrm{PSI}$

PERANCANGAN DETAIL STRUKTUR LERENG DAN PERKERASAN JALAN PADA PROYEK PENAMBAHAN LAJUR RUAS KOPO - BUAH BATU TOL PURBALEUNYI

Aghnia Monica Saniy, Syahril, Atmy Verani 
$\mathrm{Mr}$

: 3715,79 psi

$\log _{10} \mathrm{~W}_{18(10 \text { th })}=\mathrm{Z}_{\mathrm{R}} \cdot \mathrm{S}_{\mathrm{O}}+9,36 \log _{10}$

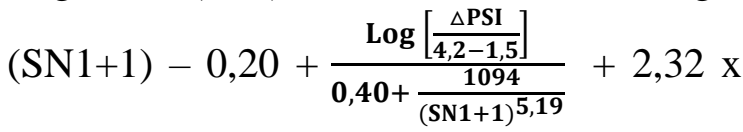

$\log _{10}(\mathrm{EBS})-8,07$

$\mathrm{SN} 1=2,3202$

$\mathrm{SN} 2=4,5487$

$\mathrm{SN} 3=7,4920$

Tebal Lapisan $1(\mathrm{D} 1)=15 \mathrm{~cm}$

Tebal Lapisan $2(D 2)=29 \mathrm{~cm}$

Tebal Lapisan $3(D 3)=40 \mathrm{~cm}$

Perhitungan tebal lapisan perkerasan 20 tahun:

Ketika umur layan selama 10 tahun telah tercapai, maka perkerasan diasumsikan memiliki kondisi sebagai berikut:

Kondisi lapis permukaan $\left(\mathrm{P}_{1}\right) \quad=50 \%$

Kondisi lapis pondasi atas $\left(\mathrm{P}_{2}\right) \quad=80 \%$

Kondisi lapis pondasi bawah $\left(\mathrm{P}_{3}\right) \quad=90 \%$

Dengan kondisi seperti di atas, maka sisa umur perkerasan 10 tahun dapat dihitung sebagai berikut:

$$
\begin{aligned}
\mathrm{SN}_{10 \text { sisa }}= & \mathrm{P}_{1} \mathrm{a}_{1} \mathrm{D}_{1}+\mathrm{P}_{2} \mathrm{a}_{2} \mathrm{~m}_{2} \mathrm{D}_{2}+\mathrm{P}_{3} \mathrm{a}_{3} \mathrm{~m}_{2} \mathrm{D}_{3} \\
\mathrm{SN}_{10 \text { sisa }}= & (0,5 \times 0,41 \times 5,91)+ \\
& (0,8 \times 0,14 \times 1,4 \times 11,42)+ \\
& (0,9 \times 0,13 \times 1,4 \times 15,42)
\end{aligned}
$$

$\mathrm{SN}_{10 \text { sisa }}=5,55$

Nilai SN sisa ini dipergunakan untuk perhitungan tebal lapisan permukaan tahap kedua (20 tahun) adalah sebagai berikut:

$$
\begin{aligned}
\mathrm{SN}_{\text {Tahap2 }} & =\mathrm{SN}_{20}-\mathrm{SN}_{10 \text { sisa }} \\
\mathrm{SN}_{\text {Tahap2 }} & =8,515-5,55=2,96 \\
\mathrm{D} 1_{\text {Tahap2 }} & =\mathrm{SN}_{\text {Tahap2 }}: \mathrm{a} 1 \\
\mathrm{D} 1_{\text {Tahap2 }} & =2,96 / 0,41=7,230 \text { inci } \\
& =18,365 \mathrm{~cm} \approx 19 \mathrm{~cm}
\end{aligned}
$$

Hasil analisa di atas dituangkan ke dalam gambar yang dapat dilihat pada Gambar 15 .

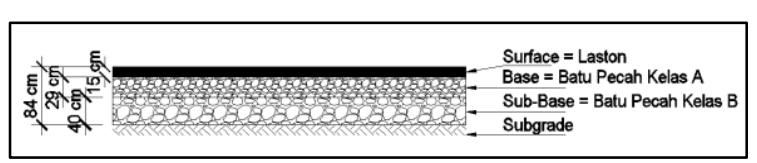

Gambar 15. Rencana Tebal Perkerasan Lentur
Dari hasil analisa, dapat dilihat bahwa tebal perkerasan lentur adalah $84 \mathrm{~cm}$ sementara tebal perkerasan pada lajur eksisting adalah $67 \mathrm{sm}$ sehingga selisih tebal adalah $17 \mathrm{~cm}$. Agar elevasi perkerasan lajur eksisting dan lajur baru sejajar, maka untuk konstruksi perkerasan lentur rencana, subgrade digali lebih dalam setinggi 17 $\mathrm{cm}$. Gambar perbandingan tebal perkerasan eksisting dan tebal perkerasan lentur rencana dapat dilihat pada Gambar 16.

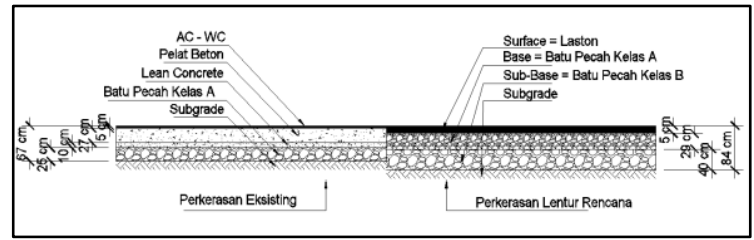

Gambar 16. Perbandingan Perkerasan Eksisting dan Perkerasan Lentur Rencana

\section{d. Perencanaan Perkerasan Kaku}

Perencanaan perkerasan paku dengan parameter dengan parameter sebagai berikut:

Fungsi jalan

Status jalan

: Arteri primer

Nasional

Jumlah Lajur Jalan Eksiting : 2 Lajur

Jumlah Lajur rencana : 3 Lajur

Lebar Lajur $\quad: 3,60 \mathrm{~m}$

Lebar bahu $\quad: 2,50 \mathrm{~m}$

Umur rencana : 20 tahun

$\mathrm{Zr}$

$:-1,282$

So

$: 0,35$

Po

$: 4,5$

$\mathrm{Pt}$

$: 2,5$

$\mathrm{J}$

$: 2,55$

$\mathrm{Cd}$

$\mathrm{Mr}$

: $3715,8 \mathrm{psi}$

K

$: 26700$

$\mathrm{Fc}$ '

Ec

$\mathrm{Sc}{ }^{\prime}$

: 663,4 psi

$\log _{10} \mathrm{~W}_{18}=\mathrm{Z}_{\mathrm{R}} \cdot \mathrm{S}_{\mathrm{O}}+7,35 \log _{10}(\mathrm{D}+1)-0,06+$ $\frac{\log \left[\frac{\Delta \text { PSI }}{4,5-1,5}\right]}{\mathbf{1}+\frac{\mathbf{1 , 6 2 4 \times 1 0 ^ { 7 }}}{(\mathbf{D}+1)^{\mathbf{8}, 46}}}+\left(4,22-0,32 \cdot \mathrm{p}_{\mathrm{t}}\right) \times \log _{10}$

PERANCANGAN DETAIL STRUKTUR LERENG DAN PERKERASAN JALAN PADA PROYEK PENAMBAHAN LAJUR RUAS KOPO - BUAH BATU TOL PURBALEUNYI

Aghnia Monica Saniy, Syahril, Atmy Verani 
$\left[\frac{\mathbf{S c} \cdot \mathbf{m}\left(\mathbf{D}^{\mathbf{0 , 7 5}}-\mathbf{1 , 1 3 2}\right)}{\mathbf{2 1 5 , 6 3 \times \mathbf { ~ J }}\left[\mathbf{D}^{\mathbf{0 , 7 5}}-\frac{\mathbf{1 8 , 4 2}}{(\mathbf{E c} / \mathbf{k})^{\mathbf{0}, 25}}\right]}\right]=\mathrm{D}=10,58$ inchi $=$ $27 \mathrm{~cm}$

- Tulangan memanjang

$\mathrm{A}_{\mathrm{s}}=\frac{\mu \cdot L \cdot M \cdot g \cdot h}{2 F s}$

$\mathrm{A}_{\mathrm{s}}=\frac{1,8 \cdot 15 \cdot 2400 \cdot 9,81 \cdot 0,27}{2 \times 240}=357,57 \mathrm{~mm}^{2} / \mathrm{m}^{\prime}$

$A_{s} \min =0,1 \% \times 270 \times 1000=270 \mathrm{~mm}^{2} / \mathrm{m}^{\prime}$

Dipergunakan tulangan diameter $12 \mathrm{~mm}$, jarak $25 \mathrm{~cm}$

- Tulangan melintang

$\mathrm{A}_{\mathrm{s}}=\frac{\mu \cdot L \cdot M \cdot g \cdot h}{2 F s}$

$\mathrm{A}_{\mathrm{s}}=\frac{1,8 \cdot 5,1 \cdot 2400 \cdot 9,81 \cdot 0,27}{2 \times 240}=121,56 \mathrm{~mm}^{2} / \mathrm{m}^{\prime}$

$A_{s} \min =0,1 \% \times 270 \times 1000=270 \mathrm{~mm}^{2} / \mathrm{m}^{\prime}$

Dipergunakan tulangan diameter $10 \mathrm{~mm}$, jarak $25 \mathrm{~cm}$

- Dowel / Ruji

Berdasarkan Tabel II.15 dengan tebal pelat $27 \mathrm{~cm}$ maka:

Diameter $=32 \mathrm{~mm}$

Panjang $=450 \mathrm{~mm}$

Jarak $=300 \mathrm{~mm}$

- Batang Pengikat

$$
\begin{aligned}
\text { At } & =204 \times \mathrm{b} \times \mathrm{h} \\
& =204 \times 0,75 \times 0,27=41,31 \mathrm{~mm}^{2} \\
\mathrm{I} & =(38,3 \times \phi)+75 \\
& =(38,3 \times 16)+75=687,8 \mathrm{~mm}=70 \mathrm{~cm}
\end{aligned}
$$

Digunakan tulangan diameter $16 \mathrm{~mm}$, panjang $70 \mathrm{~cm}$, jarak $75 \mathrm{~cm}$.

Setelah dilakukan perhitungan, maka hasil analisa di atas dituangkan ke dalam gambar yang dapat dilihat pada Gambar 17.

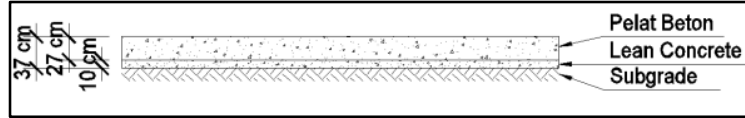

Gambar 17. Rencana Tebal Perkerasan Kaku

Dari hasil analisa, dapat dilihat bahwa tebal perkerasan kaku adalah $37 \mathrm{~cm}$ sementara tebal perkerasan pada lajur eksisting adalah $67 \mathrm{sm}$ sehingga selisih tebal adalah $30 \mathrm{~cm}$. Agar elevasi perkerasan lajur eksisting dan lajur baru sejajar, maka untuk konstruksi perkerasan kaku yang baru ditambah lapisan sub-base berupa agregat kelas A setinggi $30 \mathrm{~cm}$. Gambar perbandingan tebal perkerasan eksisting dan tebal perkerasan kau rencana dapat dilihat pada Gambar 18.

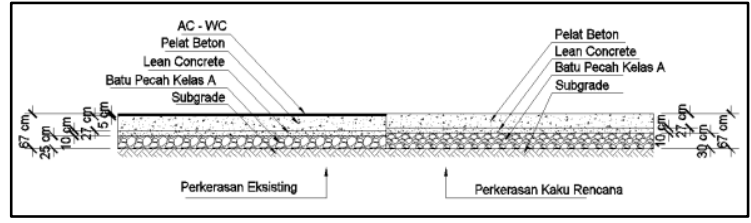

Gambar 18. Perbandingan Perkerasan Eksisting dan Perkerasan Kaku Rencana

Setelah dilakukan perhitungan perkerasan lentur dan perkerasan kaku, perkerasan yang dipilih adalah perkerasan kaku karena memiliki dimensi yang dapat disesuaikan dengan perkerasan eksisting.

\section{V.Kesimpulan dan Saran}

Kesimpulan yang dapat diambil dari hasil analisa tugas akhir adalah sebagai berikut:

1. Lereng kondisi eksting pada KM 139+925 memiliki angka keamanan menurut Bishop 0,966 dan pada KM 142+750 memiliki angka keamanan menurut Bishop 0,823.

2. Desain dinding penahan tanah untuk KM 139+925 memiliki dimensi sebagai berikut:

- Lebar dinding bagian bawah $=3 \mathrm{~m}$

- Lebar dinding bagian atas $=0,3 \mathrm{~m}$

- Tinggi total dinding penahan tanah $=4 \mathrm{~m}$

- Panjang dinding $=100 \mathrm{~m}$

Dengan ditambah dinding penahan tanah di titik ini, angka keamanan menurut Bishop menjadi 2,335.

3. Desain dinding penahan tanah untuk KM 140+750 memiliki dimensi sebagai berikut:

- Lebar didnding bagian bawah $=3 \mathrm{~m}$

- Lebar dinding bagian atass $=0,3 \mathrm{~m}$

- Tinggi total dinding penahan tanah $=4 \mathrm{~m}$

- Panjang dinding $=50 \mathrm{~m}$

Dengan ditambah dinding penahan tanah di titik ini, angka keamanan menurut Bishop menjadi 1,883 .

4. Tebal Perkerasan kaku hasil analisa adalah sebagai berikut:

- Tebal Pelat Beton $=27 \mathrm{~cm}$

- Tebal Lean concrete $=10 \mathrm{~cm}$.

- Tebal sub-base agregat kelas $\mathrm{A}=30 \mathrm{~cm}$ (untuk menyetarakan elevasi perkerasan

PERANCANGAN DETAIL STRUKTUR LERENG DAN PERKERASAN JALAN PADA PROYEK PENAMBAHAN LAJUR RUAS KOPO - BUAH BATU TOL PURBALEUNYI

Aghnia Monica Saniy, Syahril, Atmy Verani 
rencana dan perkerasan eksisting)

5. Rencana anggaran biaya untuk konstruksi hasil perancangan adalah Rp 35.000.000.000

Saran yang dapat diberikan dari tugas akhir ini adalah untuk menhan kelongsoran dapat pula digunakan teknologi baru yaitu geotekstil dan untuk pekerjaan perkerasan, dapat ditambahkan zat aditif agar beton cepat kering.

\section{Daftar Pustaka}

Badan Standarisasi Nasional. 2005. RSNI T-022005 tentang Pembebanan Untuk Jembatan. Jakarta: Badan Standarisasi Nasional.

Badan Standarisasi Nasional. 2004. RSNI T-122004 tentang Perencanaan Struktur Beton Untuk Jembatan. Jakarta: Badan Standarisasi Nasional.

Bowles, Joseph E. 1988. Foundation Analysis and Design Fourth Edition. Singapore: McGraw-Hill Book Co.

Das, Braja M. 1995. Mekanika Tanah Braja M. Das Jilid 2. Jakarta: Erlangga.

Djuwadi., Firuliadhim, Geni. 2007. Bahan Ajar Rekayasa Pondasi. Bandung: Politeknik Negeri Bandung.

Pembangunan Perumahan, PT. 2014. Petunjuk Pelaksanaan Pekerjaan Jalan Layang Paket Kebayoran Lama. Jakarta.

Nakazawa, Kazuto., Sosrodarsono, Suyono. 1994. Mekanika Tanah dan Teknik Pondasi. Jakarta: PT. Pradnya Paramita.

Setiawan, Ebta. 2012. Metodologi (online). http://kbbi.web.id [Oktober 2015]

Shouman, M. 2007. Fondasi Dalam. Bandung: Politeknik Negeri Bandung.

Sofoco. 2014. Penyelidikan Tanah Untuk Pondasi Pier Proyek Jalan Layang Paket Kebayoran Lama. Jakarta: PT. Pembangunan Perumahan.

Vesic, A.S. 1977. Design of Pile Foundation. Jakarta: Erlangga. 